\title{
Contribuições do Programa Bolsa Família para a gestão das políticas sociais
}

Elaine Cristina Licio

\section{Introdução}

Ao completar 10 anos em 2013, o Bolsa Família figura como principal programa de combate à pobreza e à desigualdade social no sistema de proteção social brasileiro, atuando por meio da transferência de renda articulada ao acesso aos serviços sociais básicos, na forma de condicionalidades. Em junho de 2013, o programa alcançava 13,7 milhões de famílias pobres, com um orçamento de cerca de $0,5 \%$ do PIB nacional.

A implementação do Programa Bolsa Família (PBF) tem mostrado muitas especificidades e evidenciado a emergência de diversas inovações no campo da gestão das políticas públicas, as quais, inclusive, se estendem aos sistemas responsáveis pela oferta dos serviços de saúde, educação e assistência social (LiCiO et al., 2011). Nesse aspecto, ressalta-se o modelo de gestão do programa, que depende fundamentalmente de uma forte coordenação federativa e intersetorial, a partir de mecanismos como o Cadastro Único e o Índice de Gestão Descentralizada (LINDERT et al., 2007, BICHIR, 2011). 
Abrucio (2011) considera que, no Governo Lula, a agenda da gestão pública foi conduzida pelas políticas públicas, citando como exemplo a forma de operação do PBF. É nesse sentido que este artigo se propõe a analisar o programa, de modo a destacar suas principais contribuições sob a perspectiva da organização do aparato estatal para o enfrentamento da pobreza e da desigualdade social.

Após reconstituir historicamente a trajetória das políticas de combate à pobreza no Brasil, apresentamos o modelo de gestão do Bolsa Família, destacando seus principais aspectos inovadores. Em seguida, especificamos suas contribuições mais importantes, como a reorientação do foco das demais políticas sociais para a população em situação de pobreza e o fortalecimento do federalismo cooperativo para implementação articulada das iniciativas voltadas para o seu público-alvo. Por fim, identificamos algumas oportunidades que o programa oferece para a gestão das políticas sociais.

\section{Histórico do enfrentamento da pobreza no Brasil}

Segundo Draibe (1994), a proteção social no Brasil estruturou-se entre as décadas de 1930 e 1970 de maneira centralizada e diretamente vinculada ao trabalho, com traços predominantemente conservadores e meritocráticos nos termos das tipologias internacionais. Tais características implicam corporativismo e clientelismo no acesso aos benefícios sociais, assim como exclusão e desigualdade social.

Até meados da década de 1990, o enfrentamento da pobreza se dava no âmbito $\mathrm{da}$ assistência social, sob o comando da Legião Brasileira de Assistência (LBA), que operava principalmente a partir da transferência de recursos federais para entidades filantrópicas, as quais se encarregavam de oferecer bens e serviços aos pobres, segundo critérios próprios de atuação. Dada sua utilização política, Sposati e Falcão (1989) consideram que o legado institucional da LBA foi de frágil institucionalização de ações nos três níveis de governo, sobretudo nas esferas subnacionais. Embora a Constituição Federal de 1988 tenha previsto que a implementação da política de assistência social se daria por meio da descentralização político-administrativa, sua regulamentação por meio da Lei Orgânica da Assistência Social (LOAS) só foi possível cinco anos depois, o que se explica em boa parte por se contrapor aos interesses dos atores preocupados em manter a forma de funcionamento clientelista e centralizada da LBA (BoschetTi, 2006).

Foi a partir de 1995, no Governo Fernando Henrique Cardoso (FHC), que o enfrentamento da pobreza ganhou diversificação a partir da definição de três estratégias principais: (1) criação do Programa Comunidade Solidária; (2) extinção da LBA; e (3) adoção de programas de transferência de renda condicionada. O Programa Comunidade Solidária consistiu na articulação de iniciativas do governo e da sociedade, tendo em vista o combate à fome e à miséria nos municípios mais pobres, sob um novo marco regulatório para atuação da sociedade na esfera pública, denominado Terceiro Setor. A extinção da LBA, por sua vez, iniciou um processo de transferência progressiva de recursos para os governos subnacionais, que passaram a atuar no apoio à implementação dos respectivos conselhos, fundos e planos de assistência social. Com isso, passou-se também a promover a regulamentação do Fundo Nacional de Assistência Social 
(FNAS), assim como organizar a formulação da nova política nacional de assistência social. Já os programas de transferência de renda condicionada surgiram como uma inovação dos governos subnacionais ${ }^{1}$, fruto do processo de fortalecimento desse nível de governo após a Constituição Federal de 1988. Inspirada nas iniciativas de Estados e Municípios, a nacionalização desses programas foi possível com o fortalecimento da União na gestão de políticas sociais na década de 1990, via medidas tributárias centralizadoras (ABrucio, 2005; Licio et al., 2011).

A partir de 1996, foram criados programas federais de transferência de renda voltados para crianças e adolescentes em situação de trabalho, como o Programa de Erradicação do Trabalho Infantil (Peti) e Agente Jovem. Também nesse período foi finalmente implementado o Benefício de Prestação Continuada (BPC), transferência de renda a idosos e deficientes prevista pela Constituição Federal oito anos antes. Em 1999, a União instituiu o Programa Federal de Renda Mínima Vinculado a Ações Socioeducativas, substituído em 2001 pelo Programa Bolsa Escola, sob coordenação do Ministério da Educação (MEC). Nesse mesmo ano, FHC passou a replicar os programas de transferência de renda em diversas outras políticas setoriais, como: o Bolsa Alimentação (2001), gerido pelo Ministério da Saúde (MS) e destinado a garantir alimentação para crianças carentes de até seis anos e para mulheres grávidas ou em fase de aleitamento; o Bolsa-Renda (2001), gerido pelo Ministério da Integração (MI), que visava a atender à população atingida pelos efeitos da estiagem na região do semiárido; e o Auxílio-Gás (2002), gerido pelo Ministério das Minas e Energia (MME), cujo objetivo era compensar as famílias de baixa renda pelo fim do subsídio ao preço do gás de cozinha.

Observa-se que a preferência por iniciativas que transferem recursos federais diretamente para o cidadão diminuiu a intermediação dos governos subnacionais e da própria sociedade civil no tradicional modelo de enfrentamento da pobreza conduzido até então pelo Governo Federal (AlmeIdA, 2005; ABrucio, 2011; BiCHIR, 2011). O surgimento desses

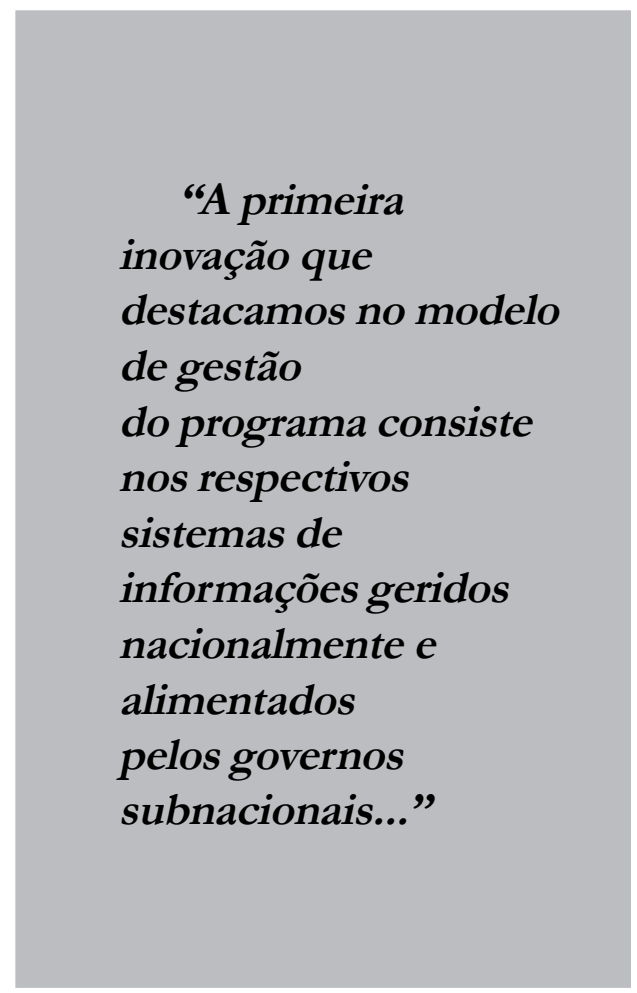

programas no rol das iniciativas federais de enfrentamento da pobreza deu-se em meio ao diagnóstico de baixo impacto das iniciativas anteriores, as quais se caracterizavam pela burocracia, clientelismo e baixa efetividade das ações realizadas por aqueles que operacionalizavam os programas, sejam eles do governo ou da sociedade. 
Esse movimento foi acompanhado da constatação de uma mudança de concepção da sociedade e do governo em relação às causas da pobreza e legitimidade para recebimento de benefícios monetários. Aos poucos, a política de combate à pobreza foi deixando de ser vista como destinada unicamente aos incapazes para o trabalho (idosos, deficientes, vítimas de calamidades etc.), passando a ser merecida por outros segmentos vulneráveis da população com situação de precária inserção no mercado, vinculada, no entanto, a condicionalidades de acesso a serviços sociais, a título de redução da transmissão intergeracional da pobreza.

Embora o tema da pobreza não tenha conquistado espaço central na agenda do Governo FHC, foi nesse período que se promoveram mudanças significativas no arcabouço institucional do seu enfrentamento, incorporando o controle social na gestão das políticas, provendo novas fontes de financiamento ${ }^{2}$, ampliando o públicoalvo e as formas de intervenções estatais.

A eleição do Presidente Lula, em 2002, reforçou a agenda de combate à pobreza e fortaleceu a opção pelos programas de transferência de renda condicionada. A avaliação do novo governo foi de que, embora esses programas tivessem representado um avanço nas políticas sociais brasileiras, eles praticamente ignoraram a existência de programas similares conduzidos por Estados e Municípios, não conseguindo superar problemas tradicionais como: pulverização de recursos, elevado custo administrativo, superposições de públicos-alvo, competição entre instituições, ausência de coordenação e de perspectiva intersetorial (CoHn e FonsECA, 2004).

Além de abranger o público-alvo dos principais programas de transferência de renda anteriores, o modelo de gestão do
PBF contempla tanto as peculiaridades federativas brasileiras, ao conjugar esforços dos três níveis de governo na sua implementação, quanto a intersetorialidade inerente a uma percepção multidimensional da pobreza, ao associar a transferência de renda ao acesso a serviços sociais de saúde, educação e assistência social na forma de condicionalidades.

\section{Modelo de gestão do Programa Bolsa Família}

Presente em todos os Estados, Distrito Federal e 5.570 Municípios brasileiros, o PBF prioriza o atendimento do público mais pobre, com renda mensal per capita de até $\mathrm{R} \$ 140$, a partir da sua inclusão na base de dados do Cadastro Único. Seus beneficiários concentram-se fortemente na Região Nordeste $(50,4 \%)$ e Sudeste $(25,3 \%)$. Nas demais regiões, os percentuais são: 5,4\% no Centro-oeste, $7,5 \%$ no Sul e $11,4 \%$ no Norte do País (Brasil, 2013a).

O programa atua por meio de três dimensões - transferência de renda, acompanhamento de condicionalidades e articulação de programas complementares -, as quais se propõem a enfrentar aspectos multidimensionais da pobreza, garantindo, respectivamente, o acesso à renda, aos serviços sociais básicos e a ações de desenvolvimento das capacidades das famílias para superação da condição de vulnerabilidade.

O valor do benefício é definido de acordo com a composição familiar e respectiva renda per capita. Atualmente, conta com quatro tipos de benefícios ${ }^{3}$.

O programa prevê a vinculação do recebimento da transferência de renda ao cumprimento de condicionalidades nas áreas de saúde e educação, quais sejam: frequência escolar de $85 \%$ para crianças e 
adolescentes entre 6 e 15 anos e de $75 \%$ para jovens de 16 e 17 anos; acompanhamento do calendário vacinal e do crescimento e desenvolvimento para crianças até 7 anos, do pré-natal para gestantes e puerpério. Tais compromissos são responsabilidades do poder público, pois se inserem em políticas definidas como direitos universais pela Constituição Federal de 1988.

Além do acompanhamento dos beneficiários do PBF aos serviços de educação e saúde, a gestão das condicionalidades inclui uma fase de repercussão do descumprimento sobre os benefícios, cujos efeitos vão desde a advertência à família, passando pelo bloqueio e pela suspensão do benefício, podendo chegar ao cancelamento. Além disso, o poder público deve identificar os motivos do não cumprimento das condicionalidades. A partir daí, são implementadas ações de acompanhamento das famílias em descumprimento, consideradas em situação de maior vulnerabilidade social. A família que encontra dificuldades em cumprir as condicionalidades deve, além de buscar orientações com o gestor municipal do programa, procurar os Centros de Referência da Assistência Social (Cras). O objetivo é auxiliá-la a superar as dificuldades enfrentadas.

O PBF articula ainda programas complementares, entendidos como ações que permitem às famílias o desenvolvimento de ativos ou capacidades geradoras de renda, possuindo papel fundamental para a efetiva superação da pobreza, ainda que sem assegurar sua inserção no mercado formal de trabalho. Nessa dimensão, todos os níveis de governo assumem o compromisso pela priorização e convergência desse tipo de programas para as famílias beneficiárias do Bolsa Família, a partir de articulação intersetorial. Atualmente, essa articulação consiste em um dos eixos de atuação do Plano Brasil Sem Miséria, estratégia federal mais ampla de enfrentamento da pobreza que abrange, além do PBF, um conjunto de ações que promovem acesso a serviços públicos nas áreas de educação, saúde, assistência social, saneamento, energia elétrica e inclusão produtiva.

Outro ator importante na gestão do PBF é a Caixa Econômica Federal (Caixa), agente operador responsável pelo pagamento da transferência de renda diretamente às famílias beneficiárias, sem a intermediação das esferas subnacionais. A Caixa tem papel estratégico no desenvolvimento e manutenção do Cadastro Único e é responsável pela logística de benefícios, a qual envolve emissão e entrega dos cartões magnéticos, manutenção da rede de pagamentos e do sistema de gestão de benefícios operado pelos gestores do programa. Desempenha ainda papel importante no apoio aos Municípios, principalmente nas questões de ordem tecnológica que afetam seus sistemas de informação.

A gestão do PBF vem sendo construída a partir de um elevado grau de interface entre União e Municípios. Enquanto a União financia e regulamenta o programa, grande parte das ações operacionais de implementação está localizada no nível municipal. As famílias beneficiárias estão em todos os 5.570 Municípios e Distrito Federal, devendo ser atendidas e acompanhadas pelos órgãos locais. O cadastramento, a gestão de benefícios, assim como a prestação dos serviços básicos de saúde, educação e assistência social e a articulação de programas complementares ocorrem nos Municípios, a partir da oferta do poder local.

A interface com os governos estaduais, além de mais recente, é um pouco mais restrita. Os Estados participam da gestão 
do PBF com a função de apoiar os Municípios com suporte tecnológico e capacitação, principalmente os menores e menos estruturados. Embora não atuem diretamente na execução do programa, a vocação dos governos estaduais para mobilização dos Municípios que estão no seu território, bem como para o monitoramento das ações realizadas, tem colocado esse nível de governo como um ator de grande relevância para o PBF, na medida em que apoia o trabalho de coordenação a cargo da União. Os Estados possuem ainda papel importante no acompanhamento das condicionalidades de educação, uma vez que boa parte das escolas públicas de ensino fundamental e médio pertence à rede estadual de ensino.

\section{Inovações}

Segundo Ana Vieira (2011), a tecnologia da informação constitui elemento essencial para o alcance dos resultados necessários ao cumprimento das metas do PBF. A primeira inovação que destacamos no modelo de gestão do programa consiste nos respectivos sistemas de informações geridos nacionalmente e alimentados pelos governos subnacionais, sobretudo pelos Municípios. Nesse sentido, destacamos: o Cadastro Único, que visa à identificação dos beneficiários e potenciais beneficiários; o Sistema de Benefícios (Sibec), cuja função é permitir que o gestor municipal execute ações de bloqueio, suspensão, cancelamento e reversão de benefícios; e os sistemas relacionados à gestão das condicionalidades - Sistema Presença, do MEC, e Bolsa Família na Saúde, do MS -, que possibilitam o registro do acompanhamento das condicionalidades do programa. Em seu conjunto, tais sistemas constituem mecanismos importantes de coordenação intra e intergovernamental, visto que trazem informações territorializadas e individualizadas sobre as famílias, permitindo o acompanhamento da trajetória das mesmas sob aspectos socioeconômicos e o acesso aos serviços sociais de saúde e educação.

O enfrentamento da pobreza, em todas as suas dimensões, vem sendo potencializado pela articulação entre as informações sobre a situação socioeconômica das famílias do PBF contidas no Cadastro Único e aquelas sobre o atendimento dessas mesmas famílias no âmbito das políticas sociais articuladas. Isso é feito por meio do Sistema de Condicionalidades (Sicon), o qual atua mediante a interoperabilidade entre o Cadastro Único, Sibec e os sistemas da educação e da saúde, com grande volume de troca de informações das respectivas ações realizadas com o público do PBF nos três níveis de governo ${ }^{4}$.

Criado em 2008, o Sicon confere ao gestor municipal maior autonomia e responsabilidade na gestão de condicionalidades do PBF, permitindo, entre outras ações, realizar consultas sobre o histórico das famílias, obter relatórios analíticos com listas de famílias em situação de descumprimento, registrar decisões sobre os recursos dos beneficiários que discordarem dos efeitos decorrentes do descumprimento, acompanhar famílias nessa situação ${ }^{5} \mathrm{e}$, inclusive, suspender os efeitos do descumprimento sobre os seus benefícios (BRASIL, 2011).

Uma segunda inovação consiste no apoio financeiro aos governos subnacionais, a partir da gestão por resultados. Desde 2006, o MDS apoia financeiramente as atividades de gestão do PBF exercidas pelos Municípios, e, desde 2008, pelos Estados, com base no Índice de Gestão Descentralizada (IGD). Esse indicador, que varia de 0 a 1 , mede quatro variáveis, duas 
relativas ao cadastramento (qualidade e atualização) e duas relativas ao acompanhamento das condicionalidades (saúde e educação). Mensalmente, o MDS apura o IGD de cada ente federado e o multiplica pelo teto de recursos previsto para o mesmo, fixado segundo a quantidade de famílias pobres. Esse repasse é feito para as áreas de assistência social, mas os recursos também podem ser gastos pelas áreas de saúde e educação, desde que aplicados na gestão do PBF. No entanto, sua prestação de contas é feita pelos conselhos de assistência social. É significativa a soma transferida aos entes federados desde a criação do IGD, em 2006, na ordem de R\$ 2 bilhões a Municípios e Estados.

Uma terceira importante inovação do programa consiste no Fórum Intersetorial e Intergovernamental de Condicionalidades do PBF, o qual é integrado por representantes dos três níveis de governo nas áreas de saúde, educação e assistência social. Oficializada em 2009, a criação do fórum sinaliza não apenas o reconhecimento da necessidade de se avançar na articulação intersetorial para enfrentamento da pobreza, mas também a importância de se coordenar a União, Estados e Municípios para isso. Embora não pretenda substituir os espaços de negociação intergovernamental próprios dos três sistemas de políticas envolvidos na gestão das condicionalidades (saúde, educação e assistência social), o fórum busca apoiar o processo decisório do PBF, proporcionando uma abordagem coletiva e simultânea dos seus aspectos intersetoriais e federativos pelos agentes envolvidos na respectiva implementação.

Tais inovações têm contribuído para que o programa obtenha resultados positivos e uma crescente legitimação junto à sociedade e aos governos subnacionais, sendo inclusive apontado como um dos responsáveis pela reeleição do Presidente Lula em 2006 (Hunter e Power, 2007; SoAres e Terron, 2008; Licio et al., 2009). Entre os seus principais resultados, destacamos aqueles que the conferiram reconhecimento nacional e internacional, como a diminuição do clientelismo local nas políticas de combate à pobreza (ALMEIDA, 2005; Abrucio, 2011; Bichir, 2011), o alto nível de focalização, além de uma efetiva contribuição para a redução da desigualdade

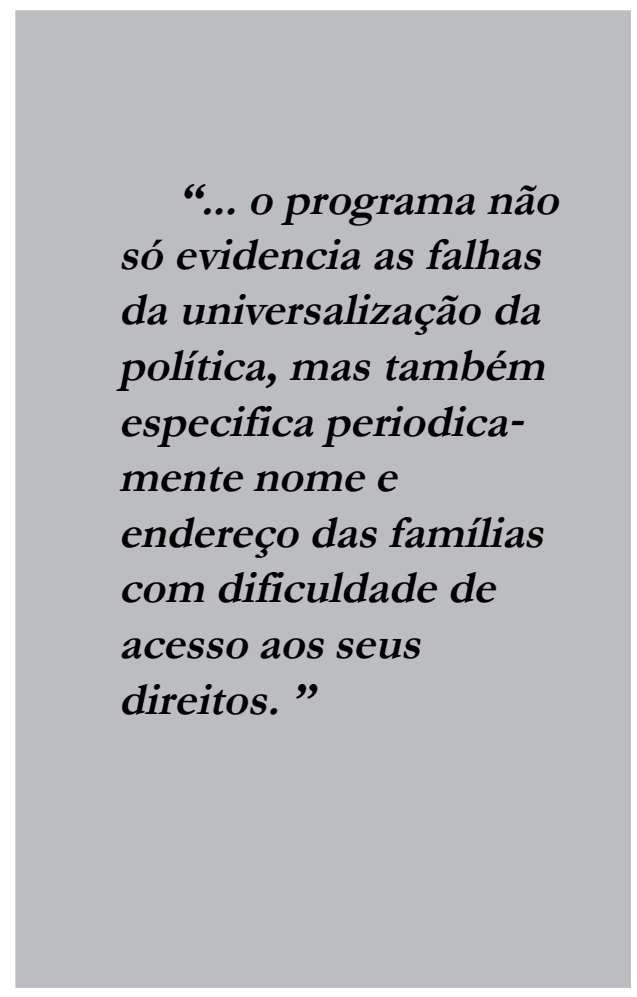

social (PAes de Barros et al., 2006; SoAres et al., 2006; Brauw et al., 2010).

\section{Contribuições para a gestão das políticas sociais}

Embora o Brasil ainda se caracterize pelos altos índices de pobreza e desigualdade social, a abordagem desse problema 
hoje é algo muito diferente do que uma década atrás, e, em grande parte, isso se deve ao Programa Bolsa Família.

Verificamos o declínio crescente da desigualdade social na última década, de forma a alcançar os menores patamares nos últimos 30 anos. Segundo Paes de Barros (2009), a partir de 2001 a renda dos mais pobres cresceu quase três vezes mais $(8 \%)$ que a média nacional $(2,7 \%)$ e quase quatro vezes mais que a renda dos mais ricos $(1,5 \%)$. Nesse período, o percentual da população vivendo em condição de pobreza absoluta caiu de $17,4 \%$ para menos de $8,8 \%$.

Para Neri (2010), embora a maior parte da responsabilidade por essa redução seja atribuída aos rendimentos do trabalho (66\%), os programas de transferência de renda, capitaneados pelo Bolsa Família, contribuíram com $17 \%$ da mesma, proporção maior que a dos tradicionais benefícios previdenciários, cuja contribuição ficou na ordem de 15\%. Segundo o autor, mesmo que possuam importância menor na renda das famílias em comparação aos rendimentos do trabalho, não deixa de ser impressionante que a contribuição desses programas para redução da pobreza e desigualdade seja visível.

Ainda que a dimensão da transferência de renda seja seu componente mais visível, o programa não a concebe como um fim em si, mas um meio para garantir o acesso aos serviços sociais básicos. Nesse sentido, ressaltamos que, para além do seu impacto direto na renda, o PBF tem um impacto importante de médio e longo prazo na redução da pobreza a partir da sua articulação com as demais políticas sociais. É dessa característica transversal que derivam suas principais contribuições para as políticas sociais, das quais identificamos duas principais. A primeira se refere ao fato de que o PBF trouxe maior foco para as demais políticas sociais. A segunda diz respeito ao fortalecimento do federalismo cooperativo previsto pela Constituição Federal de 1988, a partir da articulação do programa com os sistemas de políticas públicas de saúde, educação e assistência social.

\section{Maior foco na população pobre}

Até a criação do PBF, as políticas de combate à pobreza eram caracterizadas pela excessiva fragmentação e baixa efetividade. Todavia, sobretudo a partir do Cadastro Único e dos sistemas relacionados à gestão das condicionalidades, o PBF vem conseguindo "organizar" as famílias mais pobres individual e territorialmente, disponibilizando aos três níveis de governo informações atualizadas sobre as respectivas condições socioeconômicas (habitação, saneamento, escolaridade, renda, trabalho etc.) e acesso aos serviços previstos como condicionalidades nas áreas de educação, saúde e assistência social.

O Cadastro Único conta com mais de 23 milhões de famílias de baixa renda, das quais 13,7 milhões integram o PBF. Em virtude das condicionalidades, um contingente de milhões de cidadãos deve periodicamente ser buscado pelas políticas de saúde, educação e assistência social de forma prioritária: aproximadamente $17,5 \mathrm{mi}-$ lhões de crianças e adolescentes do PBF com perfil de acompanhamento da frequência escolar; 6 milhões de crianças (até 7 anos) e 14 milhões de mulheres (de 14 a 44 anos) com perfil de acompanhamento das condicionalidades de saúde (BRAsIL, 2013b).

O acompanhamento das condicionalidades tem apontado dificuldades de acesso às políticas universais por parte de determinadas famílias, cujos motivos 
podem ser tanto decorrentes de falhas na oferta, como relativos às condições de vulnerabilidades vividas. No caso da educação, por exemplo, entre os principais motivos que levam à baixa frequência e ao descumprimento da condicionalidade, estão o abandono/desistência $(15,1 \%)$ e a negligência dos pais (11,3\%) (BRAsIL, 2011). Portanto, o programa não só evidencia as falhas da universalização da política, mas também especifica periodicamente nome e endereço das famílias com dificuldade de acesso aos seus direitos. Esse diagnóstico "dinâmico" oferece um potencial enorme de intervenções do poder público no sentido do enfrentamento da pobreza e das múltiplas privações que a caracterizam.

Além disso, visto que as famílias em situação de descumprimento de condicionalidades são prioritárias para o acompanhamento dos serviços socioassistenciais oferecidos no Cras, O PBF em particular e o Cadastro Único de forma mais ampla têm servido de norte para a estruturação da oferta dos serviços previstos pelo Sistema Único de Assistência Social (SUAS). Da mesma forma, os programas de educação integral e alfabetização de jovens e adultos, e os programas de saúde bucal e voltados para a gestante têm adotado a inclusão no Cadastro e no PBF como um dos critérios de expansão dos seus serviços (BRAsIL, 2011).

\section{Fortalecimento do federalismo cooperativo}

Outra contribuição do PBF consiste no fortalecimento do papel dos governos subnacionais para o enfrentamento da pobreza, sobretudo dos Municípios. Sua implementação vem valorizando cada vez mais a atuação cooperativa entre os entes federativos, tendo em vista a especificação dos papéis de cada nível de governo e a criação de incentivos para atuação conjunta, a partir de estratégias de coordenação federativa (Licio et al., 2011).

Consideramos que a distribuição de responsabilidades entre os entes no federalismo brasileiro - no qual ficou destinado ao Governo Federal o poder de financiamento e regulamentação e, aos governos subnacionais, o poder de implementação - tem conduzido a um dilema que exige arranjos conciliadores: (1) da homogeneidade nacional requerida pelo Estado de Bem-estar; e (2) criação de condições de execução local compatíveis com a desigualdade social e heterogeneidade da capacidade institucional dos governos subnacionais.

A nacionalização dos programas de transferência de renda se deu sob um padrão hierarquizado de relações intergovernamentais, baseado na interface entre Governo Federal e beneficiários, com um papel secundário conferido aos governos subnacionais (Almeida, 2005; Afonso, 2006; Arretche, 2007; Fenwick, 2009; BICHIR, 2011).

Diversos fatores explicam esse movimento, que também caracterizou a gestão inicial do PBF. A Constituição Federal de 1988 colocou o enfrentamento da pobreza como um dos objetivos da República, de competência comum a todos os entes federativos, sem, contudo, precisar como se daria a cooperação entre os níveis de governo para tanto. Além disso, o desenvolvimento das políticas de enfrentamento da pobreza anteriores ao PBF e, de forma mais específica, os programas de transferência de renda por ele unificados, tradicionalmente caracterizaram-se pela centralização e fragmentação. Outro fator consiste na constatação da frágil capacidade financeira, em geral, e baixa capacidade institucional da área de assistência social nos governos 
municipais, a quem foi atribuída a tarefa de gestão do programa. No que diz respeito à engenharia operacional da política, destacamos o desenho federativo inicial concretizado pelo PBF, que pouco precisou o papel dos entes subnacionais, bem como a natureza da política de transferência de renda, que atua por meio da relação direta da União com os cidadãos para pagamento dos benefícios (Licio, 2012).

Todavia, essas condições não permaneceram durante toda a trajetória do PBF. E é a partir dessa constatação que passamos a identificar um movimento de fortalecimento do federalismo cooperativo. A centralização característica da gestão inicial do PBF é apenas uma das ações dentro do jogo federativo, o qual também convive com vetores que conduzem à descentralização, de forma a demandar uma crescente coordenação federativa, como é o caso da implementação do programa, que vem dependendo cada vez mais dos Municípios.

O PBF passou por uma crise de legitimidade em seu primeiro ano de implementação por apresentar inúmeros problemas de focalização e baixa qualidade dos procedimentos realizados pelos governos subnacionais (VIEIRA, 2011). Essa crise colocou em questão o modelo federativo centralizado adotado até então, ao evidenciar uma baixa capacidade de coordenação federativa. Dessa forma, para alcançar seus objetivos nacionais, o programa constatou que não poderia prescindir de uma participação mais efetiva dos outros níveis de governo, em particular dos Municípios. Esse movimento se deu a partir da sua articulação intersetorial com os sistemas de políticas públicas de saúde, educação e, principalmente, de assistência social, contribuindo para uma mudança no arranjo federativo do programa, no sentido da cooperação intergovernamental (Licio, 2012).
O modelo dos sistemas de políticas públicas, adotado com variações pelas políticas de saúde, educação e assistência social, orienta-se pela descentralização e implica repasses federais para financiamento da implementação subnacional, com cofinanciamento, repasses fundo a fundo e criação de espaços de deliberação intergovernamental, participação e controle social (Franzese, 2010). Essa lógica de atuação, que vem se mostrando positiva para a universalização da oferta de serviços, a princípio se chocaria com a perspectiva centralizadora da transferência de renda, evidenciando o dilema da implementação das políticas sociais no federalismo brasileiro. O PBF vem conseguindo lidar com esse dilema por meio de estratégias de coordenação federativa que induzem o fortalecimento dos governos subnacionais, de modo a melhorar o posicionamento desses entes no jogo federativo.

Num primeiro momento, essa atuação intersetorial privilegiou o SUAS, com vistas a criar condições de gestão que permitissem definir um lócus institucional para o PBF em cada um dos entes federados; especificar a atribuição de cada ente federativo na gestão do programa; e melhorar a capacidade institucional dos Municípios, de modo a garantir a implementação das diretrizes nacionais no nível local. Foram três as principais estratégias de coordenação federativa adotadas nesse sentido: (1) pactuação federativa para integração de programas de transferência de renda dos governos subnacionais ao PBF; (2) formalização da adesão dos entes federados (Estados e Municípios) ao PBF, que, assim, assumem responsabilidades de implementação; e (3) apoio financeiro à gestão descentralizada, por meio do IGD (Licio, 2012).

Aliás, em termos de coordenação federativa, a criação do IGD em 2006 foi o 
grande diferencial do programa em relação aos programas anteriores, contribuindo para a alavancagem da capacidade institucional dos Municípios mais pobres, para os quais os recursos do PBF costumam ser mais importantes.

Os avanços na regulamentação do IGD, com elevação dos padrões mínimos de desempenho, vêm contemplando prazos de adequação dos Municípios aos novos parâmetros, além de não comprometer a estabilidade dos critérios que informam seu cálculo. A regularidade no repasse dos recursos, de forma ininterrupta desde a criação do IGD, ganhou credibilidade dos Municípios e passou a efetivamente orientar a atuação municipal no programa. Tal reconhecimento foi coroado em 2009 com a transformação dessa modalidade voluntária de transferência intergovernamental, baseada em portarias, em transferência obrigatória, baseada em lei ${ }^{6}$. O repasse de recursos de livre utilização para a gestão do PBF propiciou condições favoráveis de adequação do programa às especificidades locais, sobretudo por conta da flexibilidade para sua utilização e de um processo simplificado de prestação de contas. Para isso também contribuiu a disponibilidade de sistemas de informação, o que permitiu ampliar os poderes dos Municípios no exercício das suas atribuições e conferiu maior celeridade e confiabilidade às informações sobre a trajetória das famílias no programa.

Enfim, é com base nessas estratégias que o PBF tem conseguido alcançar seu público-alvo em todo o território nacional, mesmo com toda sua complexidade de gestão e desigualdades sociais e regionais do País. Parte do sucesso dessas estratégias, evidenciada pelas diversas avaliações positivas sobre seus resultados, deve-se ao fato de ter conseguido conciliar as dimensões intergovernamental e intersetorial da sua coordenação no IGD. De forma mais incisiva, foram as estratégias de adesão e apoio financeiro à gestão descentralizada que contribuíram para ampliar a autonomia dos governos subnacionais, expandindo a legitimidade do programa junto a prefeitos e governadores.

Num segundo momento, a crescente articulação intergovernamental e intersetorial do PBF se fortaleceu na gestão das condicionalidades, no sentido de alcançar

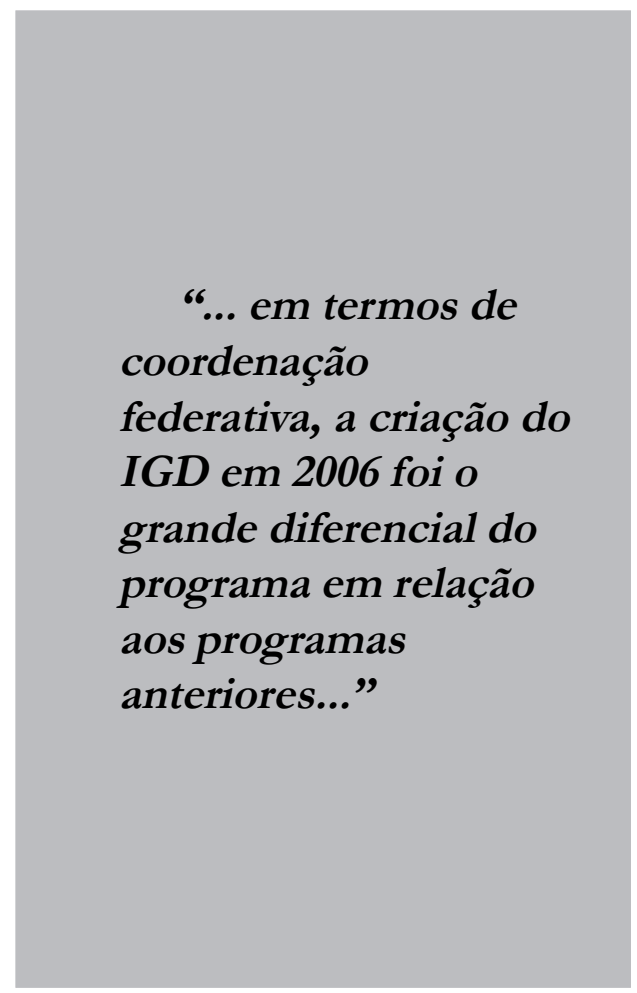

um objetivo mais ousado, consubstanciado na articulação entre o benefício e a oferta de serviços sociais básicos.

Esses serviços são de responsabilidade dos governos subnacionais, sobretudo dos Municípios, o que confere crescente importância às atribuições desse nível de governo na gestão do programa. O ensino fundamental é de responsabilidade tanto dos 
Estados quanto dos Municípios ${ }^{7}$. Já o ensino médio é de responsabilidade dos Estados. No desenho federativo do SUS, a execução dos serviços de atenção básica, que abrangem as condicionalidades do PBF, é de responsabilidade dos Municípios. Da mesma forma, a execução dos serviços socioassistenciais é de competência municipal.

Adicionalmente, contribui para nosso argumento a favor do fortalecimento do federalismo cooperativo constatar a priorização dos beneficiários do PBF em normativos próprios das políticas setoriais, pactuados nas suas respectivas instâncias de negociação federativa. Isso ocorreu no Pacto pela Vida, que define as principais políticas e metas pactuadas pelas três esferas de governo para o território nacional na saúde ${ }^{8}$, no Plano de Metas Compromisso Todos pela Educação, que visa à melhoria da educação básica'; e no Protocolo de Gestão Integrada de Serviços, Benefícios e Transferências de Renda, que prevê que as famílias em situação de descumprimento de condicionalidades integrem o público prioritário para o acompanhamento realizado pelos $\mathrm{Cras}^{10}$.

Diante disso, sintetizamos três principais variáveis que favoreceram essa maior intergovernamentalidade do programa: (1) o poder de implementação dos governos subnacionais; (2) a intersetorialidade presente na natureza do programa, sobretudo na dimensão das condicionalidades; e (3) a articulação com os sistemas de políticas públicas decorrentes dessa característica intersetorial.

Diante do dilema federativo de implementação das políticas nacionais do federalismo brasileiro, a resposta do PBF não foi centralizar ainda mais, mas sim articular-se ao SUAS, que já existia enquanto diretriz da política de assistência social, mas que ainda não tinha se estruturado nacionalmente. Essa articulação se estendeu aos sistemas de políticas da educação e da saúde e, ao mesmo tempo, ampliou a capacidade de coordenação do Governo Federal, valorizando o poder de implementação dos governos subnacionais e contribuindo para o fortalecimento da cooperação federativa, de modo a conferir maior eficiência, eficácia e efetividade ao aparato estatal de enfrentamento da pobreza.

\section{Desafios para a ampliação do acesso da população pobre às políticas sociais universais}

O PBF abriu diversas frentes de enfrentamento da pobreza. Neste artigo destacamos, sobretudo, sua articulação com os sistemas de políticas sociais universais, que, embora tenha avançado bastante desde a sua criação, apresenta diferentes resultados e desafios conforme a política analisada.

Para além de assegurar que a oferta dos serviços de educação, saúde e assistência social chegue de fato aos beneficiários do PBF no Município, um grande desafio comum aos três sistemas consiste na necessidade de se elevar os indicadores de registro do acompanhamento do acesso das famílias aos respectivos serviços. No caso da educação, estima-se que haja em torno de 1,7 milhões de crianças e adolescentes não localizados no acompanhamento $\mathrm{da}$ frequência escolar. No caso da saúde, calcula-se que cerca de 3,2 milhões de famílias não foram encontradas pelo poder público municipal, no sentido de verificar seu efetivo acesso aos serviços de saúde materno-infantil. No caso da assistência social, 9.952 famílias já estão em período 
de atenção ${ }^{11}$ para fins de acompanhamento familiar (BRASIL, 2013b).

Uma das maiores dificuldades para o aumento do registro do acompanhamento das condicionalidades hoje está na complexidade que envolve a oferta dos serviços, sobretudo nas áreas de saúde e assistência social (BICHIR, 2011). Enquanto na educação é a criança que costuma ir à escola regularmente, as demais áreas possuem uma forma mista de atuar, tanto por meio de visitas domiciliares quanto pelo atendimento em unidades locais (Unidade Básica de Saúde e Centro de Referência da Assistência Social). No caso da saúde, isso é ainda mais complicado, pois o acompanhamento das condicionalidades é um processo feito posteriormente, em momento diverso da oferta dos serviços.

Isso evidencia um tema ainda controverso entre as políticas setoriais, de que, embora se tenha avançado muito na sua universalização, elas ainda têm dificuldade de alcançar a população mais pobre (Curralero, 2012).

Dada a lógica de acompanhamento individualizado nos sistemas de informação que orientam sua gestão, o PBF materializa as falhas de universalização das políticas sociais sem, no entanto, prover instrumentos para que esse problema seja resolvido. De fato, isso está além da sua responsabilidade, sobretudo nos casos de falhas de oferta de serviços de saúde e educação, que operam em setores independentes. Todavia, tendo em vista que o PBF atua no campo da assistência social, tanto quanto o SUAS, consideramos que o programa tem potencial de contribuir, mais do que vem fazendo atualmente, para a universalização do acesso aos serviços socioassistenciais. Para isso, precisa rever suas estratégias de coordenação federativa e envolver mais os Estados e Municípios, a partir das próprias estruturas de representação dos mesmos na Comissão Intergestora Tripartite (CIT) do SUAS.

Em suma, dada a persistência de um contingente razoável de beneficiários a serem acompanhados nas políticas de saúde, educação e assistência social, as estratégias até então adotadas ainda não se mostraram suficientes para alcançar articulação plena entre a oferta dos serviços sociais básicos e o benefício do PBF.

Todavia, na dimensão das condicionalidades, o PBF conseguiu, em alguma medida, adentrar os protocolos, pactos e compromissos federativos negociados nas respectivas instâncias intergovernamentais de deliberação de cada sistema de política pública articulado. Além disso, vem conseguindo montar redes de gestores dos três níveis de governo para sua implementação no âmbito das três políticas, ainda que com diferentes níveis de mobilização e consolidação. Esses são avanços significativos em termos de organização do aparato estatal para enfrentamento da pobreza, sobretudo se considerarmos a complexidade que envolve a gestão de políticas sociais transversais em contextos federativos marcados por desigualdades regionais, como é o caso brasileiro.

(Artigo recebido em julho de 2013. Versão final em setembro de 2013). 


\section{Notas}

${ }^{1}$ As primeiras iniciativas surgiram em 1995, no Município de Campinas e no Distrito Federal. No final de 1996, havia cerca de 80 iniciativas municipais e estaduais de programas de transferência de renda condicionada em funcionamento no Brasil, todas com financiamento exclusivo dos entes federativos que as criaram (DRAIBE $e$ t al., 1998). Segundo Silva $e t$ al. (2008), apenas Municípios e Estados mais desenvolvidos apresentavam condições financeiras de manter esses programas sem auxílio externo.

${ }^{2}$ Como o Fundo Constitucional de Combate e Erradicação da Pobreza, instituído pela Emenda Constitucional no 31, de 14 de dezembro de 2000.

${ }^{3}$ Benefício Básico: o valor repassado mensalmente é de $\mathrm{R} \$ 70$ e é concedido às famílias com renda mensal de até $\mathrm{R} \$ 70$ per capita, mesmo não tendo crianças, adolescentes, jovens, gestantes ou nutrizes.

Benefício Variável: o valor é de $\mathrm{R} \$ 32$ e é concedido às famílias com renda mensal de até $\mathrm{R} \$$ 140,00 per capita, desde que tenham crianças, adolescentes de até 15 anos, gestantes e/ou nutrizes. Cada família pode receber até cinco Benefícios Variáveis, ou seja, até R\$ 160.

Benefício Variável Vinculado ao Adolescente (BVJ): é concedido valor de R\$38 a todas as famílias que tenham adolescentes de 16 e 17 anos frequentando a escola. Cada família pode receber até dois $\mathrm{BVJ}$.

Benefício para Superação da Extrema Pobreza (BSP): pago às famílias que, mesmo recebendo os benefícios financeiros do PBF, continuam em situação de pobreza extrema (renda per capita mensal de até $\mathrm{R} \$ 70)$. O valor do benefício correspondente ao necessário para que a família supere os $\mathrm{R} \$ 70$ mensais por pessoa.

${ }^{4}$ O Sicon também traz informações georreferenciadas sobre escolas, postos de saúde e Cras.

${ }^{5}$ As famílias com benefício em fase de suspensão e acompanhamento familiar registrado no Sicon entram em "Período de Atenção". Essas famílias devem ter atenção especial do poder público no período de 12 meses, para que voltem a acessar os serviços de educação e de saúde.

${ }^{6}$ Portaria GM/MDS no $148 / 2006$ e adequações. Lei n $12.058 / 2009$.

${ }^{7}$ Há variações na proporção de oferta de vagas estaduais e municipais para cada nível de ensino, de forma que, em alguns Estados, o ensino fundamental é mais municipalizado do que em outros.

${ }^{8}$ Portaria no 325/GM, de 21 de fevereiro de 2008.

${ }^{9}$ Decreto $n^{\circ} 6094 / 2007$.

${ }^{10}$ Resolução CIT/SUAS no 7, de 10 de setembro de 2009.

${ }^{11}$ Muito próximas, portanto, de perder seu benefício caso reiterem esse descumprimento. 


\section{Referências bibliográficas}

ABrucio, F. Três agendas, seus resultados e um desafio: balanço recente da administração pública federal brasileira. Desigualdade \& Diversidade - Dossiê Especial, segundo semestre de 2011, pp. 119-142.

Afonso, J. R. R. Novos desafios à descentralização fiscal no Brasil: as políticas sociais e as de transferências de renda. In: Seminário Regional de Política Fiscal, 18, 2006, Santiago. Santiago: Cepal/Ilpes, 2006.

Almeida, M. H. T. Recentralizando a federação? Revista de Sociologia e Política, n. 24, p. 29-40, 2005.

Arretche, M. A centralização no Estado Federativo Brasileiro. (Tese Livre Docência). Faculdade de Filosofia, Letras e Ciências Humanas. Departamento de Ciência Política. Universidade de São Paulo, São Paulo, 2007.

BICHIR, R. M. Mecanismos federais de coordenação de políticas sociais e capacidades institucionais locais: o caso do Programa Bolsa Família. (Tese de Doutorado). Instituto de Estudos Sociais e Políticos (IESP). Universidade do Estado do Rio de Janeiro, Rio de Janeiro, 2011.

Boschetti, I. Seguridade Social e Trabalho: paradoxos na construção das políticas de previdência e assistência social no Brasil. Brasília: Editora UNB, 2006.

Brasil. Ministério do Desenvolvimento Social (MDS). Secretaria Nacional de Renda de Cidadania (Senarc). Sobre a contribuição da gestão de condicionalidades do Programa Bolsa Família para a erradicação da extrema pobreza. Nota Técnica. Brasília, 2011.

. Ministério do Desenvolvimento Social (MDS). Secretaria Nacional de Renda de Cidadania (Senarc). Perfil das famílias beneficiárias do Programa Bolsa Família 2011. Brasília, 2013a.

- Ministério do Desenvolvimento Social (MDS). Secretaria Nacional de Renda de Cidadania (Senarc). Boletim Decon - Informativo do Departamento de Condicionalidades. N. 4. Brasília, Maio 2013b.

Brauw, A.; Gilligan, D. O.; HoddinotT; J.; Roy, S. The Impact of Bolsa Familia on Child, Maternal, and Household Welfare. International Food Policy Research Institute. Washington, DC. 2010.

Cohn, A. Fonseca, A. O Bolsa Família e a questão social. Teoria e Debate, São Paulo, n. 57, março/abril. 2004.

Curralero, C. R. B. O enfrentamento da pobreza como desafio para as politicas sociais no Brasil: uma análise a partir do Programa Bolsa Família. Tese (doutorado). Instituto de Economia. Universidade Estadual de Campinas, 2012.

Draibe, S. M. As políticas sociais do regime militar brasileiro: 1964-84. In: SOARES, G. A. D; D’ARAújo, M. C. (Ed). 21 anos de regime militar: balanços e perspectivas. Rio de Janeiro: Fundação Getúlio Vargas, p. 271-306, 1994.

Draibe, S. Fonseca, A. M. E Montali, L. Programas de Renda Mínima para Famílias Carentes: levantamento das experiências e metodologia de avaliação. Garantia de Renda Minima: ensaios e propostas. IPEA. Brasília, 1998. 
Franzese, C. Federalismo Cooperativo no Brasil: da Constituição de 1988 aos Sistemas de Políticas Públicas. (Tese de Doutorado). Escola de Administração de Empresas de São Paulo, Fundação Getúlio Vargas, São Paulo, 2010.

Fenwick, T. B. Avoiding Governors: The success of Bolsa Familia. Latin American Research Review, v. 44, n. 1, p.102-131, 2009.

Licio, E. C.; Mesquita, C. S. E Curralero, C. B. Desafios para a coordenação intergovernamental do Programa Bolsa Família. RAE, São Paulo, v. 51, n. 5, 458-470, 2011. Licio, E. C.; Castro, H. e Rennó, L. Bolsa Família e voto na eleição presidencial de 2006: em busca do elo perdido. Opinião Pública, v. 15, p. 31-54. 2009.

Licio, E. C. 2012. Para além da recentralização: os caminhos da coordenação federativa do Programa Bolsa Família (2003-2010). Tese (doutorado). Instituto de Ciências Humanas IH. Departamento de Serviço Social. Programa de Pós-Graduação em Política Social. Universidade de Brasilia - Unb, 2012.

Lindert, K. et al. The Nuts and Bolts of Brazil's Bolsa Família Program: Implementing Conditional Cash Transfers in a Decentralized Context: World Bank. Social Protection Discussion Paper, n 709, 2007.

Neri, M. C. A nova classe média: o lado brilhante dos pobres. Rio de Janeiro: FGV/CPS, 2010. Paes de Barros, R. P.; Carvalho, M.; Franco, S. e Mendonça, R. Uma análise das principais causas da queda recente na desigualdade de renda brasileira. Econômica, v.8, n. 1. p. 55-81, Jun. 2006.

Paes de Barros, R. P. Sobre a Evolução Recente da Pobreza e da Desigualdade. Instituto de Pesquisa Econômica e Aplicada (IPEA). 2009.

Silva, M. O.; Yasbek, M. C.; Di Giovanni, G. A política social brasileira no século XXI: a prevalência dos programas de transferência de renda. São Paulo: Cortez, $3^{a}$ edição, 2008.

Soares, F. V; SoAres, S.; Medeiros, M e Osório, R. G. Programas de Transferência de Renda no Brasil: impactos sobre a desigualdade. Texto para Discussão no 1228. Ipea. Brasília, 2006. SoARes, G. A. D.; Terron, S. L. Dois Lulas: a geografia eleitoral da reeleição (explorando conceitos, métodos e técnicas de análise geoespacial). Opinião Pública, v.14, p. 269-301. 2008. VieIra, A. M. M. A multiestratégia de implementação do Programa Bolsa Família e do Cadastro Único no período 2005 a 2007. (Dissertação de Mestrado). Escola Nacional de Saúde Pública Sergio Arouca. ENSP/FIOCRUZ. Rio de Janeiro, 2011. 


\section{Resumo - Resumen - Abstract}

\section{Contribuições do Programa Bolsa Família para a gestão das políticas sociais Elaine Cristina Licio}

O artigo destaca as principais contribuições do Programa Bolsa Família para a gestão das políticas sociais brasileiras, sob a perspectiva da organização do aparato estatal para o enfrentamento da pobreza e da desigualdade social. Após reconstituir historicamente a trajetória das políticas de combate à pobreza, apresenta o modelo de gestão do programa, destacando seus principais aspectos inovadores. Em seguida, especifica suas contribuições mais importantes, como o maior foco na população pobre e o fortalecimento do federalismo cooperativo para implementação articulada das iniciativas voltadas às pessoas em situação de pobreza. Por fim, identifica alguns desafios que permanecem para o programa, no que se refere à ampliação do acesso da população pobre às políticas sociais universais.

Palavras chave: federalismo; intersetorialidade; políticas sociais

\section{Contribuciones del Programa Bolsa Família para la gestión de las políticas sociales brasileñas \\ Elaine Cristina Lício}

El artículo destaca las principales contribuciones del Programa Bolsa Familia para la gestión de las políticas sociales brasileñas desde la perspectiva de la organización del aparato estatal para combatir la pobreza y la desigualdad social. Después de la reconstrucción de la trayectoria histórica de las políticas de lucha contra la pobreza, se presenta el modelo de gestión del programa, destacando sus principales aspectos innovadores. A continuación, especifica sus contribuciones más importantes, como centrarse en los pobres y el fortalecimiento del federalismo cooperativo articulado para la implementación de las iniciativas a las personas en situación de pobreza. Finalmente, identifica algunos de los retos pendientes para el programa relacionados con el aumento del acceso de los pobres a las políticas sociales universales.

Palabras clave: federalismo; intersectorialidad; políticas sociales

\section{Contributions of the Bolsa Familia Program for the management of Brazilian soci al policies \\ Elaine Cristina Lício}

The article highlights the main contributions of the Bolsa Família Program for the management of Brazilian social policies from the perspective of the organization of the state to combat poverty and social inequality. After historically reconstruct the trajectory of policies to combat poverty, presents the management model of the program, highlighting its main innovative aspects. Then specifies his most important contributions, as focus on the poor and strengthening of cooperative federalism articulated for implementation of initiatives to people in poverty situation. Finally, it identifies some of the challenges that remain for the program in order to increase poor people access to universal social policies.

Keywords: federalism; intersectoriality; social policies 


\section{Elaine Cristina Lício}

É doutora em política social pela Universidade de Brasília (UnB) e integrante da carreira de Especialista em Políticas Públicas e Gestão Governamental (EPPGG), em exercício no Ministério do Desenvolvimento Social e Combate à Fome (MDS).Contato: elaine.licio@gmail.com 